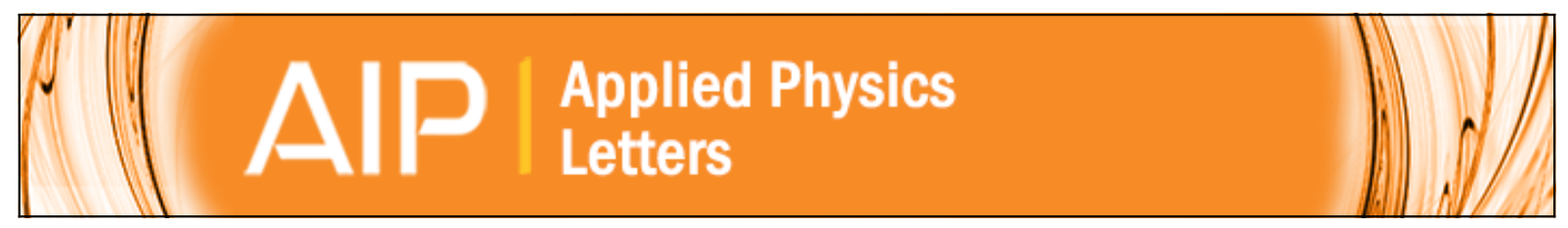

\title{
Millisecond minority carrier lifetimes in n-type multicrystalline silicon
}

Andres Cuevas, Mark J. Kerr, Christian Samundsett, Francesca Ferrazza, and Gianluca Coletti

Citation: Applied Physics Letters 81, 4952 (2002); doi: 10.1063/1.1529089

View online: http://dx.doi.org/10.1063/1.1529089

View Table of Contents: http://scitation.aip.org/content/aip/journal/apl/81/26?ver=pdfcov

Published by the AIP Publishing

\section{Articles you may be interested in}

On the low carrier lifetime edge zone in multicrystalline silicon ingots

J. Appl. Phys. 115, 012007 (2014); 10.1063/1.4837998

Dependence of phosphorus gettering and hydrogen passivation efficacy on grain boundary type in multicrystalline silicon

J. Appl. Phys. 114, 244902 (2013); 10.1063/1.4856215

Empirical correlation for minority carrier lifetime to defect density profile in germanium on silicon grown by nanoscale interfacial engineering

J. Vac. Sci. Technol. B 31, 051201 (2013); 10.1116/1.4816488

Investigating minority carrier trapping in n-type $\mathrm{Cz}$ silicon by transient photoconductance measurements

J. Appl. Phys. 111, 053101 (2012); 10.1063/1.3689786

Bulk minority carrier lifetimes and doping of silicon bricks from photoluminescence intensity ratios

J. Appl. Phys. 109, 083111 (2011); 10.1063/1.3575171

\section{AlP $\mid$ APL Photonics}

APL Photonics is pleased to announce Benjamin Eggleton as its Editor-in-Chief

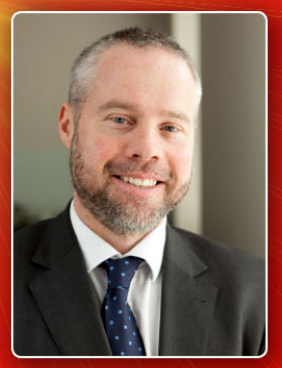




\title{
Millisecond minority carrier lifetimes in $n$-type multicrystalline silicon
}

\author{
Andres Cuevas, ${ }^{\text {a) }}$ Mark J. Kerr, and Christian Samundsett \\ Faculty of Engineering and I.T., The Australian National University, Canberra ACT 0200, Australia \\ Francesca Ferrazza and Gianluca Coletti \\ Eurosolare, SpA, V. D'Andrea 6, 00048 Nettuno, Italy
}

(Received 23 September 2002; accepted 22 October 2002)

\begin{abstract}
Exceptionally high minority carrier lifetimes have been measured in $n$-type multicrystalline silicon (mc-Si) grown by directional solidification and subjected to phosphorus gettering. The highest effective lifetimes, up to $1.6 \mathrm{~ms}$ averaged over several grains and $2.8 \mathrm{~ms}$ within some of them, were measured for relatively lowly doped, $2-3 \Omega \mathrm{cm}$, wafers. The lifetime was found to decrease for lower resistivities, still reaching $500 \mu$ s for $0.9 \Omega \mathrm{cm}$ and $100 \mu$ s for $0.36 \Omega \mathrm{cm}$. Several important findings are reported here: (i) achievement of carrier lifetimes in the millisecond range for $\mathrm{mc}-\mathrm{Si}$, (ii) effectiveness of phosphorus gettering in $n$-type mc-Si, and (iii) demonstration of good stability under illumination for $n$-type mc-Si. (C) 2002 American Institute of Physics.
\end{abstract}

[DOI: $10.1063 / 1.1529089]$

Multicrystalline silicon (mc-Si) has become the prevalent material used by the solar cell industry, representing more than $50 \%$ of its total annual production. Different methods exist to fabricate mc-Si, usually in the form of large parallelepipeds that are cut into smaller ingots and then into wafers. The directional solidification method used in this work produces large $\mathrm{mm}$ to $\mathrm{cm}$ size, grains. Twins, dislocations, and other crystallographic defects are, nevertheless, common within the grains. In addition, metallic impurities, carbon, and oxygen are usually present. Industrially manufactured mc-Si is predominantly $p$ type and boron doped. The simultaneous presence of boron and oxygen can lead to a bistable effect whereby the lifetime degrades upon exposure to natural or artificial light. This effect is a serious limitation for Czochralski (CZ) grown $p$-type, boron-doped silicon. A similar light induced degradation has also been documented for some mc-Si materials. ${ }^{1}$ These results may not be directly extrapolated to other types of mc-Si since, in some processes, the oxygen content can be kept relatively low, thus decreasing the risk of degradation. In any case, a more robust solution to the degradation problem is to use $n$-type material, whose stability has been proven for CZ silicon, irrespective of its oxygen content. ${ }^{2}$ The study of the electronic properties of $n$-type mc-Si presented here indicates that the quality of this material is, or can be made, exceptional.

Specific processing steps, including phosphorus diffusion and aluminum alloying, have a cleansing effect and are able to remove metallic contaminants from the silicon wafers, thus improving their lifetime. Such gettering techniques are present in some form in most commercial fabrication processes. They have always been behind the record efficiencies and lifetimes reported for mc-Si. Among the latter, for $p$-type $\mathrm{mc}-\mathrm{Si}$, it is worth noting intragrain minority carrier lifetimes of up to $135 \mu$ s for $0.65 \Omega \mathrm{cm}$ (Ref. 3) and $190 \mu \mathrm{s}$ for $0.8 \Omega \mathrm{cm} .{ }^{4}$ Nagel et al. ${ }^{1}$ measured an average lifetime of $140 \mu$ s for $1 \Omega \mathrm{cm}$ using a microwave detected photoconduc-

${ }^{a)}$ Electronic mail: andres.cuevas@anu.edu.au tive decay (PCD) technique, with some grains showing 400 $\mu$ s. Our own quasisteady-state measurements of $p$-type mc-Si include effective lifetimes up to $260 \mu \mathrm{s}$ in $1.5 \Omega \mathrm{cm}$ material, averaged over several grains. ${ }^{5}$ The separation between surface and bulk recombination indicated a bulk lifetime of $600 \mu \mathrm{s} .^{6}$

The $n$-type mc-Si studied here was grown at Eurosolare SpA in a commercial directional solidification furnace following the standard conditions used for the production of $p$-type ingots. The growth conditions used were similar to those of the conventional boron-doped material. The silicon feedstock consisted of the top and tail parts of electronic quality CZ Si ingots, both $n$ type and, to a smaller extent, $p$ type. The $n$-type conductivity of the mc-Si ingot, which we verified by the hot point probe test, was the result of light compensation between both dopant types. As a consequence of the low segregation coefficient of phosphorus $(0.35$, compared to 0.8 for boron), the concentration of phosphorus along $n$-type ingots, both $\mathrm{CZ}-\mathrm{Si}$ and $\mathrm{mc}-\mathrm{Si}$, is not uniform and increases in the direction of the solidification. As shown in Fig. 1, the resistivity measured as a function of wafer position within the mc-Si ingot varies from approximately 3 $\Omega \mathrm{cm}$ at the bottom to $0.33 \Omega \mathrm{cm}$ at the top. Whereas the 12.5 $\mathrm{cm}$ long ingot yielded a total of 250 wafers, only 50 wafers (one out of every five) are included in Fig. 1. The resistivity was measured with the same contactless conductance instrument used for the minority carrier lifetime measurements described next.

The $100 \mathrm{~cm}^{2}$ wafers from Eurosolare were cut in smaller pieces of about $25 \mathrm{~cm}^{2}$ for processing and etched in a mixture of nitric and hydrofluoric acids to remove possible surface damage and contamination. Some samples received a phosphorus gettering at $880^{\circ} \mathrm{C}$ for $1 \mathrm{~h}$ using a relatively high $\mathrm{POCl}_{3}$ concentration ratio in the diffusion furnace. This $40-55 \Omega /$ sq diffusion was subsequently etched and a new light phosphorus diffusion at $840^{\circ} \mathrm{C}$, was performed to create $250 \Omega /$ sq $n$-type regions on both sides of the samples. A thin oxide was thermally grown at $880^{\circ} \mathrm{C}$ for $20 \mathrm{~min}$ in the same furnace, followed by a $400{ }^{\circ} \mathrm{C}$ anneal in a forming gas 


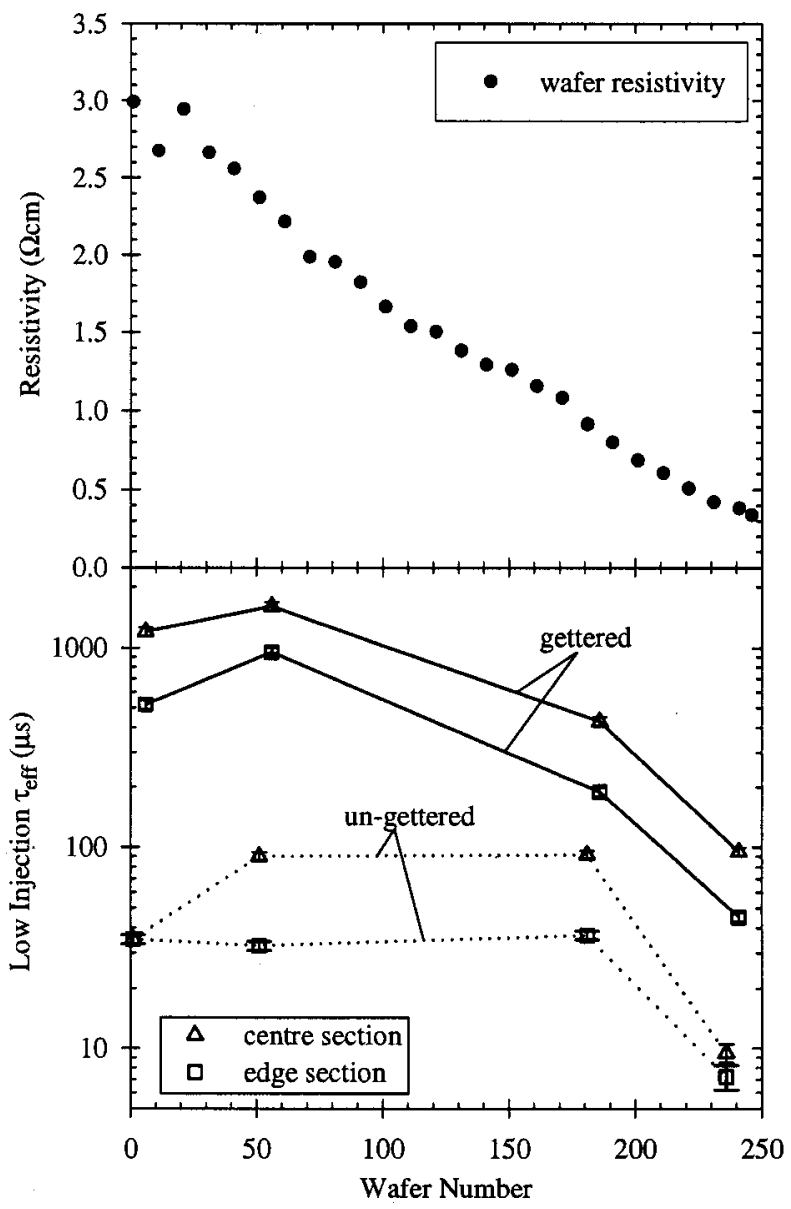

FIG. 1. Variation of the resistivity and $\tau_{\text {eff }}$ of $n$-type mc-Si as a function of ingot position, for both gettered and ungettered wafers. Samples were taken from both the edge and center of the ingot.

$\left(95 \% \mathrm{Ar}, 5 \% \mathrm{H}_{2}\right.$ ). The combination of a lightly diffused region and an oxidized surface minimizes surface recombination. Despite the passivation of the surfaces, their contribution cannot be totally discounted, and the lifetimes reported here should be considered as effective lifetimes.

The effective minority carrier lifetime of $n$-type mc-Si wafers from four different positions along the ingot, both with and without a gettering treatment, is also shown in Fig. 1 . Without gettering, the lifetimes are in the range of $70 \mu \mathrm{s}$ for $3 \Omega \mathrm{cm}$ material to $10 \mu$ s for the $0.36 \Omega \mathrm{cm}$ wafers. It is interesting to note that wafers nearest the bottom and the top of the ingot have a lower lifetime than those in the broad central region. After gettering, the bottom wafers essentially became identical to the lower center wafers which, in turn, reveal themselves to be superior to those from the upper center wafers. The effect of the phosphorus gettering was spectacular, with several wafers exceeding the millisecond lifetime mark, and all of them benefiting from it. The best result is for a $2.3 \Omega \mathrm{cm}$ wafer, whose average lifetime of 1.6 $\mathrm{ms}$ corresponds to a hole diffusion length of $1.4 \mathrm{~mm}$. The lifetimes after gettering decrease with decreasing resistivity, a trend commonly seen in single-crystalline silicon. In particular, some $0.9 \Omega \mathrm{cm}$ wafers exhibited lifetimes of about $500 \mu \mathrm{s}$, and $0.36 \Omega \mathrm{cm}$ wafers; $100 \mu \mathrm{s}$.

The effective lifetime as a function of the excess carrier density is shown in Fig. 2 for several representative wafers. The curve for the $0.36 \Omega \mathrm{cm}$ ungettered wafer shows strong

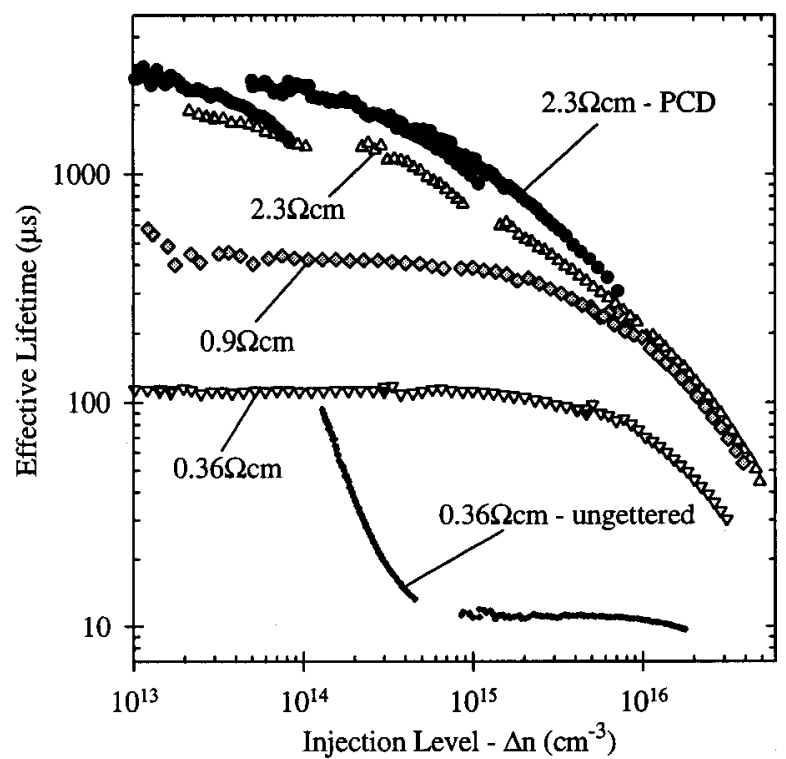

FIG. 2. Injection level dependence of $\tau_{\text {eff }}$ for gettered center sections of $n$-type mc-Si of different resistivities. All measurements are QSSPC with 4 ms flash, except the upper curve, labeled PCD. As shown for the $0.36 \Omega \mathrm{cm}$ case, phosphorus gettering greatly improves the lifetime and removes trapping centers.

trapping at carrier densities below $10^{15} \mathrm{~cm}^{-3}$. These trapping effects, ${ }^{7}$ which are frequently associated with the presence of metallic impurities, disappear with the gettering treatment. The lifetime increases by a factor of 10 and remains practically constant over a broad range of injection levels, which is a very desirable feature for solar cell operation. A similar behavior is found for the postgettering lifetime of the $0.9 \Omega \mathrm{cm}$ wafer, except at high carrier densities where the lifetime is affected by Auger and emitter region recombination.

In the case of the $2.3 \Omega \mathrm{cm}$ wafer, also shown in Fig. 2, there is a significant difference between the lifetimes measured by either the photoconductance decay $(\mathrm{PCD})^{8}$ or the quasisteady-state photoconductance (QSSPC) $)^{9}$ techniques, with PCD values of $2.8 \mathrm{~ms}$, compared to $1.6 \mathrm{~ms}$ for the QSSPC lifetime. We have found a similar discrepancy between PCD and QSSPC lifetimes in $p$-type mc-Si. ${ }^{6}$ The higher lifetimes obtained with the PCD method are representative of the best intragrain regions, while the QSSPC method gives an area-weighted average value over several grains. The sensing coil of the conductance instrument has a diameter of $2 \mathrm{~cm}$ and covers an area of approximately $3 \mathrm{~cm}^{2}$ which, in all cases studied here, includes several grains and grain boundaries. The QSSPC method is based on the balance between generation and recombination, while the illumination on the sample is varied slowly. In this study, we have used a xenon flash that varies exponentially with a characteristic rate of $4 \mathrm{~ms}$ and has a total duration of $12 \mathrm{~ms}$. Neutral density filters were used to attenuate the light and explore a broad range of light intensities. Using a control high resistivity float zone (FZ) wafer, we also measured the saturation current density of the two light phosphorus diffusions present at the surfaces of these wafers, $J_{o e}$ $=50 \mathrm{fA} / \mathrm{cm}^{2}$. This imposes a limit of $3.2 \mathrm{~ms}$ on the measurable lifetime in a $2.3 \Omega \mathrm{cm} n$-type wafer, which indicates that 


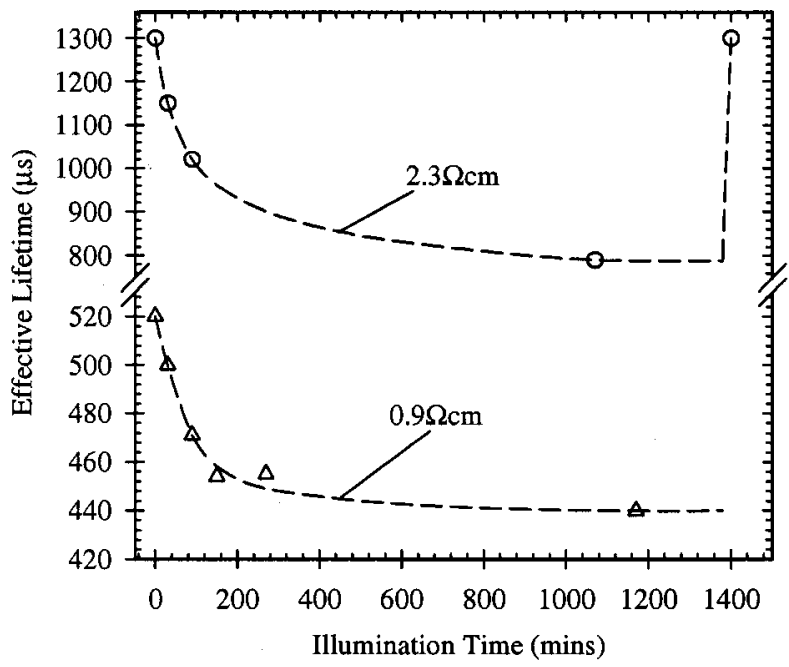

FIG. 3. Light induced degradation in gettered $n$-type mc-Si. The degradation is quite mild with stable effective lifetimes of $440 \mu$ s and $800 \mu$ s measured for $0.9 \Omega \mathrm{cm}$ and $2.3 \Omega \mathrm{cm}$ materials, respectively. The lifetime of the 2.3 $\Omega \mathrm{cm}$ sample recovered after a $400{ }^{\circ} \mathrm{C}$ anneal.

the $1.6 \mathrm{~ms}$ average and $2.8 \mathrm{~ms}$ intragrain lifetimes are probably surface limited.

Light exposure experiments where carried out to evaluate the stability of the measured lifetimes. Selected mc-Si wafers were exposed to light from a halogen lamp with an intensity equivalent to the standard solar spectrum (100 $\mathrm{mW} / \mathrm{cm}^{2}$ ), while maintaining their temperature at 25 $\pm 2{ }^{\circ} \mathrm{C}$. A FZ control wafer with identical surface conditions (light phosphorus diffusion and oxidation) was also exposed to verify that the passivation did not suffer any degradation. Lifetime measurements were taken at regular intervals, as shown in Fig. 3. A relatively mild degradation was observed for a $2.3 \Omega \mathrm{cm}$ wafer, with its maximum lifetime dropping from 1.3 to $0.8 \mathrm{~ms}$ after $18 \mathrm{~h}$ of light exposure. The lifetime fully recovered after a forming gas anneal at $400{ }^{\circ} \mathrm{C}$, a behavior that is typical of the boron-oxygen complexes believed to be responsible for the light induced degradation of boron-doped $\mathrm{CZ}$ silicon. This recovery also excludes $\mathrm{FeB}$ pairs as a possible cause. The degradation observed in this $n$-type mc-Si may be thought to be associated with the residual boron still present in the wafers, together with a concentration of oxygen that tends to be highest at the bottom of the mc-Si ingots. Nevertheless, it is logical to expect that the concentration of boron should be much lower (probably by more than a factor of 10) than that of phosphorus, that is, lower than $2 \times 10^{15} \mathrm{~cm}^{-3}$ in this $n$-type wafer. $\mathrm{CZ}$ silicon doped with a similar amount of boron would have a resistivity of $7 \Omega \mathrm{cm}$ and suffer a lifetime degradation of about $50 \% .{ }^{10}$ A $0.9 \Omega \mathrm{cm}$ sample from the upper part of the ingot degraded only marginally, from 530 to $440 \mu$ s after $19.5 \mathrm{~h}$. The stable lifetimes of up to $800 \mu$ s and $440 \mu$ s are at a sufficiently high level as to consider $n$-type mc-Si stable in practice. In comparison, measurements by Nagel et al. ${ }^{1}$ of 1 $\Omega \mathrm{cm} p$-type mc-Si showed a degradation from 140 to $70 \mu \mathrm{s}$. The lifetime of $1 \Omega \mathrm{cm}$ boron-doped CZ silicon typically degrades by more than a factor of 5 , with final lifetimes of $10-20 \mu \mathrm{s} .{ }^{10}$

The minority carrier lifetimes for the $n$-type mc-Si material of different resistivities measured here are truly exceptional, reaching similar levels to $n$-type monocrystalline silicon, which are in the range of $1.1-6 \mathrm{~ms}$ for $0.6-1.5 \Omega \mathrm{cm} .{ }^{11}$ They prove that high-quality mc-Si can be grown by simple methods, using reject silicon, in commercial furnaces. The $0.5-1.6 \mathrm{~ms}$ average lifetimes measured in phosphorus gettered wafers with resistivities in the $0.9-3 \Omega \mathrm{cm}$ range imply minority carrier diffusion lengths greater than $0.7 \mathrm{~mm}$, that is, more than three times the typical final wafer thickness. These results open the way for a class of silicon solar cells based on $n$-type mc-Si. High efficiency devices, including rear junction and bifacial designs, are certainly feasible using material of such quality. Based on the experiments presented here, these devices should be stable under illumination.

This work has been partially supported by the Australian Research Council.

${ }^{1}$ H. Nagel, J. Schmidt, A. G. Aberle, and R. Hezel, Proceedings of the 14th European Photovoltaic Solar Energy Conference, Barcelona, Spain, 1997, p. 762.

${ }^{2}$ J. Schmidt, A. G. Aberle, and R. Hezel, Proceedings of the 26th IEEE Photovolt. Spec. Conf. (IEEE, Washington, 1997), p. 13.

${ }^{3}$ A Rohatgi, S. Narashima, S Kamra, P. Doshi, C. P. Khattak, K. Emery, and H. Field, Proceedings of the 25th IEEE Photovoltaic Specialists Conf. (IEEE, Washington, 1996), p. 1554.

${ }^{4}$ P. Lölgen, A. Rohatgi, P. Sana, W. C. Sinke, A. C. Weeber, C.Leguijt, R. A. Steeman, and J. A. Eikelboom, Proceedings of the 12th European Photovoltaic Solar Energy Conf., Amsterdam, Holland, 1994, p. 1778.

${ }^{5}$ A. Cuevas, M. Stocks, S. Armand, M. Stuckings, A. Blakers, and F. Ferrazza, Appl. Phys. Lett. 70, 1017 (1997).

${ }^{6}$ A. Cuevas, M. Stocks, D. Macdonald, M. Kerr, and C. Samundset, IEEE Trans. Electron Devices 46, 2026 (1999).

${ }^{7}$ D. Macdonald and A. Cuevas, Appl. Phys. Lett. 74, 1710 (1999).

${ }^{8}$ G. L. Miller, D. A. H. Robinson, and J. D. Wiley, Rev. Sci. Instrum. 47, 799 (1976).

${ }^{9}$ R. A. Sinton and A. Cuevas, Appl. Phys. Lett. 69, 2510 (1996).

${ }^{10}$ J. Schmidt and A. Cuevas, J. Appl. Phys. 86, 3175 (1999).

${ }^{11}$ M. J. Kerr and A. Cuevas, Semicond. Sci. Technol. 17, 35 (2002). 